\title{
TUBERCULOUS LYMPHADENITIS? A RETROSPECTIVE AND PROSPECTIVE STUDY
}

\author{
Rajesh Daniel1, Levi Mark², Mohan Verghese ${ }^{3}$, Jasbir Dhanoa ${ }^{4}$, Jeyakumar 5 , M. Mustafa ${ }^{6}$, Paneerselvam $^{7}$ \\ ${ }^{1}$ Assistant Professor, Department of General Surgery, SRM Medical College Hospital and Research Center, Kattankulathur, \\ Kancheepuram, Tamilnadu. \\ ¿2 Surgeon Commander, Department of General Surgery, Indian Navy, Katari Bagh, Naval Base, Kochi. \\ ${ }^{3}$ Retired Professor, Department of General Surgery, Christian Medical College and Hospital, Ludhiana, Punjab. \\ ${ }^{4}$ Retired Professor, Department of General Medicine, Christian Medical College and Hospital, Ludhiana, Punjab. \\ 5 Professor and HOD, Department of General Surgery, SRM Medical College Hospital and Research Center, Kattankulathur, \\ Kancheepuram,Tamilnadu. \\ ${ }^{6}$ Professor, Department of General Surgery, SRM Medical College Hospital and Research Center, Kattankulathur, \\ Kancheepuram, Tamilnadu. \\ ${ }^{7}$ Retired Professor, Department of General Surgery, SRM Medical College Hospital and Research Center, Kattankulathur, \\ Kancheepuram, Tamilnadu.
}

\section{ABSTRACT}

\section{BACKGROUND}

Tuberculous lymphadenitis is the commonest cause of lymphadenopathy in developing countries. This study was conducted to analyse the clinical presentation, complications and recurrences in patients presenting with tuberculous lymphadenitis.

\section{MATERIALS AND METHODS}

This descriptive study is based on the observation of two groups of patients: a retrospective and prospective group of patients attending the outpatient department and the patients admitted in Christian Medical College \& Hospital, Ludhiana. The retrospective group included all patients over 12 years of age who had presented with lymphadenopathy and were diagnosed as tuberculous lymphadenitis and their medical records reviewed. The prospective group were clinically examined, haematological and histopathological investigations were carried out. They were followed up for assessment of complications.

\section{RESULTS}

A total number of 171 cases were qualified to be included in this study. Patients with matted lymph nodes constituted $53.8 \%$ and discrete lymph nodes constituted $46.2 \%$. Lymph nodes with a firm consistency constituted a significant proportion of $74.9 \%$ compared with lymph nodes with soft and hard consistencies constituting $20.5 \%$ and $4.7 \%$ respectively. Cervical node involvement was there in $70.7 \%$ of patients. The mean lymph node size was $6.9 \mathrm{~cm}$ with a variation between $0.5-20 \mathrm{~cm}$. Nearly $38 \%$ of them had positive reaction for PPD. Chest X-ray findings were normal in $57.9 \%$ of patients. Nearly $50 \%$ of patients had fever as the chief complaint.

\section{CONCLUSION}

There was a significant preponderance to cervical lymph node involvement. The consistency of lymph nodes was firm in a majority of cases. BCG vaccination was not protective against tuberculous lymphadenitis. Clinical presentations were diverse and the clinical diagnosis was difficult to establish.

\section{KEYWORDS}

Tuberculous Lymphadenitis, Lymph Node, Clinical Presentation.

HOW TO CITE THIS ARTICLE: Daniel R, Mark L, Verghese M, et al. Tuberculous lymphadenitis? a retrospective and prospective study. J. Evolution Med. Dent. Sci. 2017;6(52):3947-3950, DOI: 10.14260/Jemds/2017/854

\section{BACKGROUND}

Though tuberculosis continues to afflict man since Neolithic times. In recent years, there has been a significant resurgence, particularly of its extrapulmonary variants and multi-dug resistant forms. ${ }^{1}$ Tuberculosis is the greatest killer disease worldwide next to HIV/AIDS. ${ }^{2}$ In 2013, 9 million people fell ill with TB and 1.5 million died from the disease. ${ }^{3}$ Tuberculosis is a major public health problem among the developing countries of the world and tuberculous lymphadenitis is the most common cause of chronic lymph

Financial or Other, Competing Interest: None.

Submission 23-05-2017, Peer Review 22-06-2017,

Acceptance 16-06-2017, Published 29-06-2017.

Corresponding Author:

Dr. Rajesh Daniel,

\#6, Church Lane, $3^{\text {rd }}$ Lane,

Ritherdon Road, Vepery, Chennai-600007.

E-mail: rajeshdaniel1112@gmail.com

DOI: $10.14260 /$ jemds $/ 2017 / 854$ node enlargement. ${ }^{4}$ Extrapulmonary tuberculosis constitutes nearly $15-20 \%$ of overall tuberculosis cases and also is an important clinical problem. ${ }^{5}$

The diagnosis of extrapulmonary tuberculosis is more difficult to establish than pulmonary tuberculosis due to protean nature of the disease and the lack of simple screening tests, whereby a high incidence of suspicion is necessary for establishing the diagnosis of extrapulmonary tuberculosis. ${ }^{6}$

Tuberculous lymphadenitis is one of the most common manifestations of extrapulmonary tuberculosis. It accounts for about $30 \%$ of all cases of predominantly extrapulmonary disease and about $5 \%$ of all cases of tuberculosis. ${ }^{7}$ It represents a localised process, or an expression of a disseminated disease, occurring either as a result of primary infection or by extension from a contiguous focus. ${ }^{8}$ It is characterised by regional lymph node involvement of areas draining the primary focus of infection with or without constitutional symptoms such as fever, weight loss, night sweats, malaise and fatigue. 
Although tuberculosis is a common clinical entity, the significant resurgence in its incidence in recent years of both its pulmonary and extrapulmonary variants, particularly TB lymphadenitis is a cause for analysing the incidence, pattern of disease, clinical presentation, diagnostic workup, complications and recurrences in patients presenting with TB lymphadenitis.

\section{MATERIALS AND METHODS}

This descriptive study was conducted in the SRM Medical College and Hospital, Kattankulathur. Data collection was done during a nine-year retrospective period extending from November 2004 to November 2013 and a 1-year prospective period extending from December 2013 to November 2014. This study included all patients diagnosed as tuberculous lymphadenitis. A patient was defined as having tuberculous lymphadenitis based on the clinical examination and characteristics of the lymph node, FNAC or excisional biopsy of the affected lymph nodes with histopathological examination of the affected lymph nodes and the lymph node tissue along with haematological determinants of the disease.

\section{Exclusion Criteria for the study included the following-}

1. Patients presenting with the other causes of lymphadenopathy, e.g. lymphoma, leukaemia, secondary carcinomatous deposits, etc.

2. Patients diagnosed elsewhere as tuberculous lymphadenitis but presenting with related problems.

3. Patients under 12 years of age.

General physical examination of each patient was performed including local examination of the lymph nodes involved. Haemoglobin estimation was done using cyanmethemoglobin method, total leukocyte count by immunocytometry method and ESR estimation by Wintrobe's method. PPD test was carried out with 0.1 unit of purified tuberculin injected intradermally over the anterior aspect of the forearm. The site of the injection was inspected after 48 hours. The test was considered positive when the size of the induration was more than $10 \mathrm{~mm}$; weakly positive, when the size of the induration was approximately $8-10 \mathrm{~mm}$ and negative when the size of the induration was less than $8 \mathrm{~mm}$.

FNAC was done as per the technique described by Orell et al. The slides containing the aspirates were stained by ZiehlNeelsen technique and looked for acid-fast bacilli under microscopic examination. Microscopic appearance in tuberculous lymphadenitis includes clusters of histiocytes of epithelioid cell type and multinucleated giant cells of Langhans type.

Excision biopsy was done in all patients presenting with tuberculous lymphadenitis with an inconclusive FNAC report, in patients with deep seated lymph nodes in whom FNAC was difficult to obtain and in patients with cold abscesses and persistent discharging sinuses. The excised lymph node tissue was sent for histopathological examination. Microscopically, the normal architecture of the lymph node is replaced by granulomas of varying sizes comprising a central area of caseation necrosis, surrounded by epithelioid cells, lymphocytes, few Langhans giant cells, few plasma cells and histiocytes.

The patients in the prospective group were monitored carefully for established clinical and laboratory parameters as delineated in the protocol. They were followed up over monthly intervals on the basis of regression. Complications and recurrences if any, were noted. The medical records of the patients in the retrospective group were studied to determine the clinical presentations and outcome of the disease.

\section{RESULTS}

This descriptive study is based on the observation of a retrospective and prospective group of diagnosed cases of tuberculous lymphadenitis who sought care from Christian Medical College \& Hospital, Ludhiana. The retrospective group comprised 200 patients and the prospective group comprised 27 patients.

Of the 227 Patients, the following were excluded from both the Retrospective and Prospective study Groups as the number was Too small for a Comparative Study-

1. Forty patients who did not follow up after confirmation of diagnosis and commencement of treatment.

2. Five patients with mediastinal lymph nodes.

3. Eight patients with mesenteric lymph nodes.

4. Two patients receiving only Rifampicin, INH and Streptomycin.

5. Six patients receiving PAS, ethionamide and thioacetazone in addition to Rifampicin, INH, Streptomycin, Ethambutol and Pyrazinamide.

In this descriptive study, male:female ratio was more or less equal with 85 males representing $49.7 \%$ and 86 females representing $50.3 \%$. The mean age of the study participants was 29.9 years with $\mathrm{SD}=13.5$ and age ranged between 13 to 78 years. There were $33(19.3 \%)$ patients with a previous history of tuberculosis, $50(29.2 \%)$ patients with a history of systemic illness and $24(14 \%)$ patients with a family history of tuberculosis. In this study, 82 patients had received BCG (48\%).

In this study, palpable swelling constituted the chief complaint in all patients. In addition, 93 patients complained of fever (49.5\%). (Table 1 ).

\begin{tabular}{|c|c|c|}
\hline Complaints & Number & Percentage \\
\hline Palpable swelling & 171 & 100 \\
\hline Cough & 68 & 36.2 \\
\hline Fever & 93 & 49.5 \\
\hline $\begin{array}{c}\text { Loss of } \\
\text { weight/Appetite }\end{array}$ & 88 & 46.8 \\
\hline Fatigue/Malaise & 34 & 18.1 \\
\hline Pain & 19 & 10.1 \\
\hline
\end{tabular}

In this descriptive study, 92 patients presented with matted lymph nodes $(53.8 \%)$ and greater proportion of them had firm consistency (74.9\%). (Table 2). In this study, 7 patients presented with discharging sinus, constituting $4.1 \%$ and 34 patients presented with cold abscess (19.7\%).

\begin{tabular}{|c|c|c|}
\hline Lymph Node & Number & Percentage \\
\hline Presentation & & \\
\hline 1. Matted & 92 & 53.8 \\
\hline 2. Discrete & 79 & 46.2 \\
\hline Consistency & & \\
\hline \multicolumn{2}{|l}{} \\
\hline
\end{tabular}




\begin{tabular}{|cl|c|c|}
\hline 1. & Soft & 35 & 20.5 \\
\hline 2. & Firm & 128 & 74.9 \\
\hline 3. Hard & 8 & 4.7 \\
\hline \multicolumn{2}{|c|}{ Table 2. Lymph Node Presentation } \\
\hline
\end{tabular}

\begin{tabular}{|c|c|c|}
\hline Site & Number & Percentage \\
\hline Cervical & 133 & 70.7 \\
\hline Supraclavicular & 33 & 17.6 \\
\hline Submental & 12 & 6.4 \\
\hline Axillary & 43 & 22.9 \\
\hline Inguinal & 9 & 4.8 \\
\hline Epitrochlear & 5 & 2.7 \\
\hline Submandibular & 18 & 9.6 \\
\hline Jugulodigastric & 9 & 4.8 \\
\hline Parotid & 2 & 1.1 \\
\hline Scalene & 1 & 0.5 \\
\hline \multicolumn{2}{|c|}{ Table 3. Lymph Node Distribution } \\
\hline
\end{tabular}

Observations from the study indicate that there were 133 (70.7\%) patients presenting with cervical lymph nodes followed by $43(22.9 \%)$ patients with axillary lymph nodes (Table 3). The mean lymph node size was $6.95 \mathrm{~cm}(\mathrm{SD}=3.9$ ) and range was $0.5-20 \mathrm{~cm}$.

\begin{tabular}{|c|c|c|}
\hline Investigation & Number & Percentage \\
\hline \multicolumn{3}{|l|}{ PPD test } \\
\hline 1. Positive & 36 & 38.3 \\
\hline 2. Weakly positive & 47 & 50.0 \\
\hline 3. $\quad$ Negative & 11 & 11.7 \\
\hline \multicolumn{3}{|l|}{ Chest X-ray } \\
\hline 1. $\quad$ Normal & 99 & 57.9 \\
\hline $\begin{array}{ll}\text { 2. } & \text { S/O pathology } \\
& \text { other than TB }\end{array}$ & 40 & 23.4 \\
\hline $\begin{array}{l}\text { 3. S/O } \\
\text { Tuberculosis }\end{array}$ & 32 & 18.7 \\
\hline \multicolumn{3}{|l|}{ FNAC } \\
\hline 1. Conclusive & 72 & 42.1 \\
\hline 2. Nonconclusive & 99 & 57.9 \\
\hline \multicolumn{3}{|l|}{ Histopathology } \\
\hline Done & 100 & 58.5 \\
\hline Not Done & 71 & 41.5 \\
\hline
\end{tabular}

In this descriptive study, it was observed that 94 patients had received PPD of which 36 patients had a positive reaction constituting 33.8\%, 72 patients had conclusive FNAC findings and 32 patients had chest X-rays suggestive of tuberculosis pathology (Table 4). It was noted from the study that there was a significant number of patients, 83 without complications constituting 40.8\%, 29 patients developed dissemination (17\%). Three patients (7.8\%) developed dissemination of disease following failure of compliance (Table 5). It was noted that 33 patients $(17.6 \%)$ developed recurrence. Observation from the study indicated that complete regression of nodes was present in only 57 patients (33\%) while it was persistent in 114 patients (67\%).

\begin{tabular}{|c|c|c|}
\hline Complication & Number & Percentage \\
\hline Drug reaction & 25 & 14.6 \\
\hline Failure of compliance & 18 & 10.5 \\
\hline Dissemination & 29 & 17 \\
\hline Drug reaction/Dissemination & 11 & 6.4 \\
\hline Failure of compliance/Dissemination & 3 & 1.8 \\
\hline None & 83 & 40.5 \\
\hline
\end{tabular}

\section{DISCUSSION}

It was observed that the ratio between patients with matted lymph nodes and those with discrete lymph nodes was more or less equal. Studies done by several authors, Domb \& Chole, ${ }^{9}$ Deitel, ${ }^{10}$ Alleva et al, ${ }^{11}$ Castro et al ${ }^{12}$ show that there is no significant/particular pattern of presentation of lymph nodes. Domb, Chole and Deitel observed greater frequency of matted lymph nodes whereas Alleva et al \& Castro et al observed significant percentage of discrete lymph nodes.

On comparing the consistency of lymph nodes, it was observed that lymph nodes with firm consistency constituted $74.9 \%$. Newcombe ${ }^{13}$ in his series demonstrated that most patients in tuberculous lymphadenitis presented with lymph nodes of firm to soft consistency.

From the observation made during this study, it was found that cervical lymph nodes constituted a significant proportion $(70.7 \%)$, axillary $(22.9 \%)$, supraclavicular (17.6\%), submandibular (9.6\%), submental (6.4\%), inguinal and jugulodigastric (4.8\%) each. Several authors including Domb \& Chole, ${ }^{9}$ Deital and Seldonha, ${ }^{10}$ Alleva et al ${ }^{11}$ Davaris et $\mathrm{al}^{14}$ in previous literatures observed that there was no typical nodal involvement. However, in a study by Weir and Thornton, ${ }^{6}$ it was observed that there was a preponderance to cervical lymph node involvement in tuberculous lymphadenitis.

In this study, patients presenting with discharging sinus constituted only $4.1 \%$ and patients presenting with cold abscess constituted $19.9 \%$. Jones and Campbell ${ }^{15}$ in a case study of 122 patients reported that patients presenting with discharging sinus constituted $13.1 \%$ and patients with cold abscesses constituted $11.5 \%$. Lau et al(16) reported that patients with cold abscesses and discharging sinuses constituted $21.3 \%$.

The mean lymph node size was $6.9 \mathrm{~cm}$ with a standard deviation of 3.9 and range between $0.5-20 \mathrm{~cm}$. Castro et al ${ }^{12}$ reported a mean size of $9 \mathrm{~cm}$ in previous series. Hooper ${ }^{17}$ in a review of 118 cases reported mean size of the lymph node as $6 \mathrm{~cm}$. In this study, it was observed that there was no significant difference between those patients who had received BCG immunisation (48\%) and those patients who had not received BCG immunisation (52\%). Edwards ${ }^{18}$ in his series demonstrated a decrease in incidence of TB lymphadenitis in patients who had received BCG vaccination. However, Glassroth et al (1980) indicated that divergent results had been obtained with BCG immunisation in different field trials and that there was no substantial explanation for it.

Observations made from this study indicated that of the 94 patients diagnosed as tuberculous lymphadenitis, who had received PPD, patients with a positive reaction constituted $38.29 \%$, while patients with a weakly positive reaction constituted $50 \%$ and patients with a negative reaction 
constituted $11.7 \%$. According to previous literature, Castro et al $^{12}$ reported that it was sufficient to make a presumptive diagnosis of tuberculous lymphadenitis in patients with a positive PPD and enlarging neck masses in conjunction with other factors. Davaris et al, ${ }^{14}$ Ord and Matz, ${ }^{19}$ Stoneburner ${ }^{20}$ demonstratedthat PPD was often positive in cases diagnosed as tubercular lymphadenitis.

Observations from this study showed that chest X-ray findings were normal in a significant number of patients (57.9\%). Observations by different authors, Ord and Matz, ${ }^{19}$ Alleva et al,11 Castro et al ${ }^{12}$ in previous literature mention that a significant proportion of patients with tubercular lymphadenitis had a normal chest X-ray. Davaris et $\mathrm{al}^{14}$ in a review found that there were positive chest X-rays in less than $50 \%$ of patients diagnosed as tubercular lymphadenitis.

In this study, patients with an FNAC conclusive of tubercular lymphadenitis constituted $42.1 \%$ while patients with an inconclusive FNAC constituted $57.9 \%$. Patients who underwent HPE constituted 58.5\%. However, Malaker et al ${ }^{21}$ comparing the efficacy of FNAC and HPE reported sensitive and specificity rate of $79 \%$ to $94.5 \%$ in the diagnosis of tubercular lymphadenitis by FNAC.

From this study, the chief presenting complaints in decreasing order of frequency were fever constituting (49.5\%), loss of appetite \& weight constituting (46.8\%), cough (36.7\%), fatigue and malaise (18.1\%) and pain/tenderness constituting only about $10.1 \%$.

In a study by Ahmed and Kheiry, ${ }^{22}$ it was reported that the common presenting symptoms in decreasing order of frequency were fever (89\%), loss of appetite and weight (77\%) and cough (35\%). Patients presenting with constitutional symptoms in addition to local areas of lymphadenopathy was also reported by Weir and Thornton (1985). However, Alleva et $\mathrm{al}^{11}$ and Shafer et $\mathrm{al}^{7}$ in their series, reported that constitutional symptoms were uncommon. Richter et $\mathrm{al}^{23}$ and Shafer et $\mathrm{al}^{7}$ also observed that the majority of lymph nodes were painless in a series of case studies done by them.

\section{CONCLUSION}

There was a significant preponderance to cervical lymph node involvement. The consistency of lymph nodes was firm in a majority of cases. BCG vaccination was not protective against tuberculous lymphadenitis. Clinical presentations were diverse, and the clinical diagnosis was difficult to establish.

\section{REFERENCES}

[1] Gabbay E, Cameron D, Lake FR. Tuberculous lymphadenitis: revisiting an old foe. Aust Nz J Med 1996;26(4):561-2.

[2] URL-

http://www.who.int/mediacentre/factsheets/fs104/en.

[3] URL-

http://www.who.int/tb/publications/globalreport/en.

[4] Laishram RS, Devi RKB, Konjengbam R, et al. Aspiration cytology for the diagnosis of tuberculous lymphadenitis: a five year study. J Indian Acad Clin Med 2010;11:31-5.
[5] Sharma SK, Mohan A. Extrapulmonary tuberculosis. Indian J Med Res 2004;120(4):316-53.

[6] Weir RM, Thomton FG. Extrapulmonary tuberculosis. Experience of community hospital and review of the literature. The American Journal of Medicine 1985;79(4):467-78.

[7] Shafer RW, Chirgwin KD, Glatt AE. HIV prevalence, immunosuppression, and drug resistance in patients with tuberculosis in an area endemic for AIDS. AIDS 1991;5:399-405.

[8] Sewell CL, Byrd RP, Roy TM, et al. Tuberculous lymphadenitis in the adult. J Ky Med Assoc 1997:95(5):197-9.

[9] Domb GH, Chole RA. The diagnosis and treatment of scrofula (mycobacterial cervical lymphadenitis). Otolaryngol Head and Neck Surg 1980;88(4):338-41.

[10] Deitel M, Seldonha CF, Borowy ZJ, et al. Treatment of tuberculous masses in the neck. Can J Surgery 1984;27(1):90-3.

[11] Alleva M, Guida RA, Romo T, et al. Mycobacterial cervical lymphadenitis: a persistent diagnostic problem. Laryngoscope 1988;98(8 Pt 1):855-7.

[12] Castro DJ, Hoover L, Zuckerbraun L, et al. Cervical mycobacterial lymphadenitis. Medical vs surgical management. Arch Otolaryngol 1985;111(12):816-9.

[13] Newcombe JF. Tuberculosis cervical lymphadenitis. Postgrade Med J 1971;47(553):713-7.

[14] Davaris P, Ragos B, Papagiannopoulos N, et al. Mycobacterial cervical lymphadenitis: a clinicopathological study of 3 cases. Journal of Craniomaxillofacial surgery 1994;22(3):177-81.

[15] Jones PG, Campbell PE. Tuberculous Lymphadenitis in childhood. British Journal of surgery 1974;1:302-43.

[16] Lau SK, Kwan S, Lee J, et al. Source of tubercle bacilli in cervical lymph nodes: a prospective study. Journal of laryngology and otology 1991;105(7):558-61.

[17] Hooper AA. Tuberculous peripheral lymphadenitis. Br J Surg 1972;59(5):353-9.

[18] Edwards A. Tuberculosis, a growing health problem. Health Dialogue 1996;7:1-2.

[19] Ord JR, Matz JG. Tuberculous cervical lymphadenitis. Arch Otolaryngol 1974;99(5):327-9.

[20] Stoneburner RL. Tuberculosis and acquired immunodeficiency syndrome-New York City. JAMA 1988;259(3):338-45.

[21] Malakar D, Jajoo ILN, Swarup K, et al. A clinical evaluation of fine needle aspiration cytology in the diagnosis of lymphadenopathy. Ind J Tub 1991;38:179.

[22] Ahmed J, Kheiry J. Cervical lymphadenopathy in khartoum. Journal of Tropical Medicine and Hygiene 1992;95(6):416-9.

[23] Richter C, Kitinya JN, Kimara SJ, et al. Clinical characteristics of tuberculous lymphadenitis in Tanzania. Tropical Doctor 1992;22(3):129-30. 